\title{
Geographical Detector Model for Influencing Factors of Industrial Sector Carbon Dioxide Emissions in Inner Mongolia, China
}

\author{
Rina $\mathrm{Wu}^{1}{ }^{1}$, Jiquan Zhang ${ }^{1, *}$, Yuhai Bao ${ }^{2, *}$ and Feng Zhang ${ }^{1}$ \\ 1 College of Environment, Northeast Normal University, Changchun 130024, China; \\ wurn835@nenu.edu.cn (R.W.); Zhangf093@nenu.edu.cn (F.Z.) \\ 2 Inner Mongolia Key Laboratory of Remote Sensing and Geographic Information, Huhhot 010022, China \\ * Correspondence: zhangjq022@nenu.edu.cn (J.Z.); baoyuhai@imnu.edu.cn (Y.B.); \\ Tel.: +86-431-8509-9992 (J.Z.); +86-471-439-3373 (Y.B.)
}

Academic Editor: Jack Barkenbus

Received: 7 November 2015; Accepted: 2 February 2016; Published: 5 February 2016

\begin{abstract}
Studying the influencing factors of carbon dioxide emissions is not only practically but also theoretically crucial for establishing regional carbon-reduction policies, developing low-carbon economy and solving the climate problems. Therefore, we used a geographical detector model which is consists of four parts, i.e., risk detector, factor detector, ecological detector and interaction detector to analyze the effect of these social economic factors, i.e., GDP, industrial structure, urbanization rate, economic growth rate, population and road density on the increase of energy consumption carbon dioxide emissions in industrial sector in Inner Mongolia northeast of China. Thus, combining with the result of four detectors, we found that GDP and population more influence than economic growth rate, industrial structure, urbanization rate and road density. The interactive effect of any two influencing factors enhances the increase of the carbon dioxide emissions. The findings of this research have significant policy implications for regions like Inner Mongolia.
\end{abstract}

Keywords: geographical detector model; influencing factors; carbon dioxide emissions; industrial sector

\section{Introduction}

Since the 1990s, capital and energy consumption industry has started to spring up and the carbon dioxide emissions from energy consumption have increased significantly. However, carbon dioxide emissions resulting from energy consumption caused a series of problem such as declining environmental quality, global warming and climate change and so on. Hence, understanding the relationship between carbon dioxide emissions and its influencing factors has become the most important issues in recent years [1,2]. To cope with the emission issues, in 2009, the Chinese government announced it would reduce its $\mathrm{CO}_{2}$ emissions per unit of GDP by $40 \%-45 \%$ in 2020 from 2005 [3]. How to reduce carbon dioxide emissions yet, all the while, maintain stable economic growth has not just given rise to heated rhetoric but has also been one of the major concerns of energy and environmental protection policy in every corner of the world [4].

Thus, it is not only an issue that state government pays attention to, also what the academic groups needs to care about. In 1970s, American ecologist Ehrlich P.R. et al. [5] using IPAT model to evaluate environment pressure, which indicates that population, average wealth and technology would have the most impact on environment. In 1994, York et al. [6] create a special and unique form and take the population, wealth and technology variation into consideration based on IPAT and STIRPAT model to analysis the factors impacting on carbon dioxide emissions. In China, a great many scholars used STIRPAT model to evaluate the influence of social economic factor on carbon 
dioxide emissions. For example, in 2009, Lin S.F. et al. [7] analyzed the influencing factors on Chinese environment based on STIRPAT model. The results show that the influencing factor impact on Chinese environment was population > urbanization level $>$ GDP per capita > industrial level > energy intensity. To our limited degree, there is little research on the energy consumption carbon dioxide emissions from social economic factors and different industrial sector in Inner Mongolia northeast of China. Furthermore, the previous research and models were limited to "single factor", which means the total amount of carbon dioxide emissions is only concern to one factor. Therefore, there is a lack of studies on the interactive effect of two or more social economic factors influence on carbon dioxide emissions. Whether counties with different industrial sectors display different influencing patterns on the increase of carbon dioxide emissions is also unknown.

In recent research, the influence analysis can be conducted using various methods, such as the EKC concept [8], decomposition analysis (IDA/SDA) [9,10], LMDI model analysis [11] and so on. In this paper, we study the influence of social economic factors on carbon dioxide emissions in industrial sector at a macro level. For doing so, we use a relatively new mathematical programming methodology, called the geographical detector model which is proposed by Wang et al. [12] of assessing relationship between the carbon dioxide emissions and social economic factors by approach of spatial variance analysis (SVA). The basic idea of SVA is to measure the degree to which the spatial distribution of carbon dioxide emissions is consistent with that of influencing factors (e.g., GDP, road density, industrial structure, etc.). As a novel spatial analysis method, the geographical detector method does not require any assumptions or restrictions with respect to explanatory and response variables [13]. An excellent feature of the geographical detector method is that it can deal with qualitative data, while the classic regression model has some limitations on analyzing qualitative data when there are too many categories $[13,14]$. The geographical detector model consists of four detector i.e., factor detector, interaction detector, risk detector, and ecological detector etc. Four detectors were proposed to assess the main and interactive effect of influence factors on carbon dioxide emissions by using concept of Power of Determinant $(P D)$. The risk detector was used to calculate the geographical area under carbon dioxide emissions. The factor detector was used to assess which determinants are responsible for the carbon dioxide emissions. The ecological detector determined if there is a significant difference between the effects of different influencing factors on carbon dioxide emissions. The interactive detector was used to analyze whether multi determinants independently or dependently affect the carbon dioxide emissions [12]. All four detectors can be easily implemented using the software Geo-Detector [15]. Therefore, we first identify and map the spatial distribution of the carbon dioxide emissions and influencing factors at the county level. Then, we employ the four detectors to assess the association between carbon dioxide emissions and those social economic factors and make discussion in terms of the results. We believe that the model is further implication within the carbon system field.

The remainder of this paper is organized as follows: In Section 2, we give a brief discussion of the definitions of the variables, data description and describes the geographical detector model. In Section 3 presents the theoretical structures and the empirical results. Finally, Section 4 concludes and discusses the future work and policy implication.

\section{Materials and Methodology}

\subsection{Data Resources and the Definitions of the Variables}

The seven variables used in this paper includes carbon dioxide emissions, GDP, population, economic growth rate, urbanization rate, industrial structure and road density from 101 counties in the Inner Mongolia, China. The statistics data choose from the Inner Mongolia Statistic Yearbook year (2012) [16]. The summary statistics (mean value and standard deviation) of carbon dioxide emissions, GDP, population, economic growth rate, urbanization rate, industrial structure and road density are presented in Figure 1. The carbon dioxide emissions data for each county are calculated from the energy consumption multiplied by each fuel coefficient. Eight types of fuels were considered in this research, 
including coal, coke, crude oil, gasoline, kerosene, diesel oil, fuel oil and natural gas, respectively. In order to avoid repetitive computation, consumption of electricity is not considered in this computation because this fuel is generated in one industrial process and combusted in other industrial processes. The GDP is defined as the ratio of total finished products of economy and labor value produces in a certain period of time (a season or a year) of a country or a region. It is often regards as the best indicator to measure the economic development of a country. The industrial structure defined as the ratio of secondary industry GDP and total industries GDP, which is the constitution of all industrial sectors of national economy and the proportion among all industries. The economic development level generally refers to the degree of a country or a region's economic growth. The economic development requires energy consumption and it has strong impact on carbon dioxide emissions. Population refers as the total population $(10,000)$ in each county. Population growth may bring about increasing carbon dioxide emissions. The economic growth rate is the ratio of former year of GDP and latter year of GDP. It is a great indicator that can determine the economic development period of a region, and may refer to different features of energy demand and energy use efficiency in different times. The road density is defined as the ratio of the total length of all road types and the overall area of the region. The more complex of a regional traffic, the more developed the region economy it is. The greenhouse gas which produces from energy consumption with economic development is also the main factor of causing climate change. In the global greenhouse gas emissions, the urban traffic accounted for $13.1 \%$, and the transportation sector is the third largest emissions department only behind the energy supply and industrial production department [17]. Finally, urbanization is in essence a process of population aggregation [18]. In this paper measure the urbanization rate by calculating the proportion of non-farm population in total population in each county. The urbanization rate is a modernized indicator which affects the carbon dioxide emissions level indirectly and standards the social development level of a region [19]. Studies show that the urbanization rate leads to an overall energy consumption level increase and affects the level of carbon dioxide emissions indirectly. Therefore, there is a positive correlation between carbon dioxide emissions and the rate of urbanization [20].

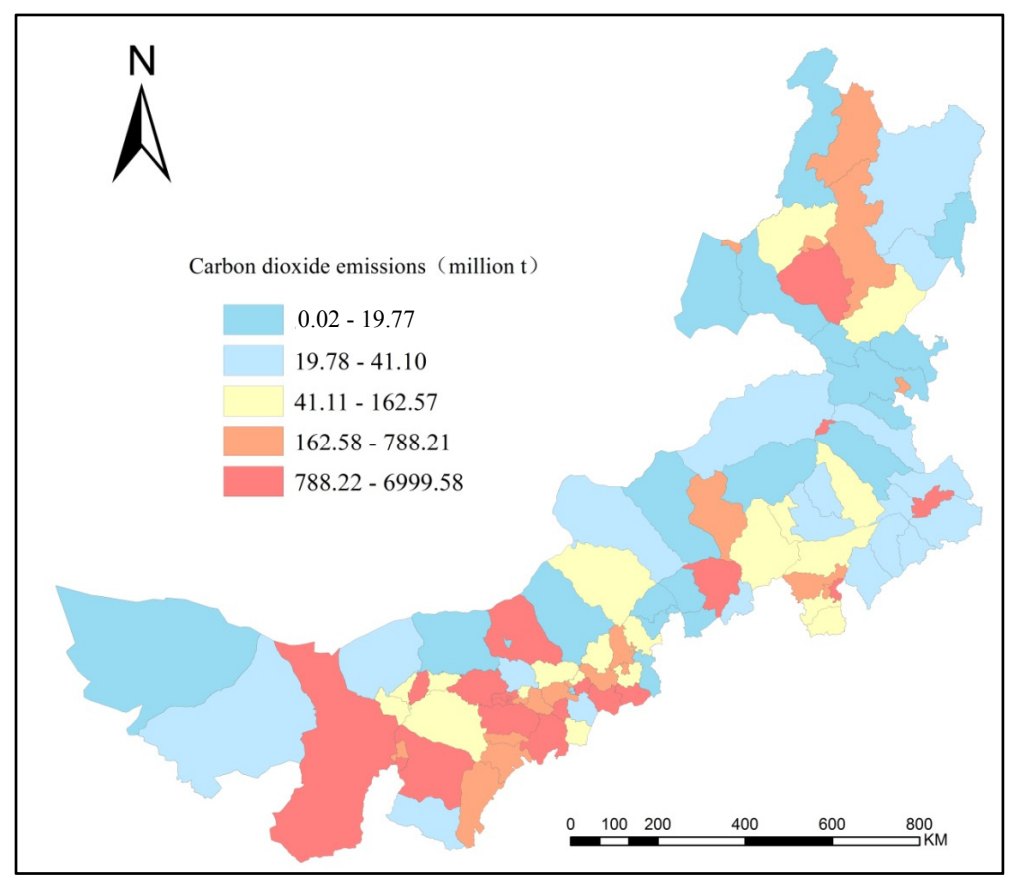

Figure 1. The spatial distribution of carbon dioxide emissions at the county level in Inner Mongolia, China. 


\subsection{The Methodology}

The geographical detectors model proposed by Wang et al. [12] is based on spatial variance analysis (SVA). Geographical detector is software based on spatial variation analysis of the geographical strata of variables to assess the social economic factors impact on the carbon dioxide emissions. We assume that the carbon dioxide emissions would exhibit a spatial distribution similar to that of influencing factors if the influencing factor leads to the carbon dioxide emissions [13]. The mechanism is quantified by the power value as follows.

We denote geographic space as $\Omega$ and geographic distribution of the carbon dioxide emissions as $H$. The whole geographic space is divided into $N_{T}$ units by regular grids and carbon dioxide emissions in each unit are $H_{i}\left(1 \leqslant i \leqslant N_{r}\right)$. The space distribution of the carbon dioxide emission affecting factor, which can be divided into $n_{D}$ sub-region in the geographic space, is $D$. The carbon dioxide emission $(H)$ and influencing factor $(D)$ determine $n_{D}$ sub-regions in the whole geographical space under the overlaying effects of GIS, and each sub-region had $n_{D, Z}\left(1 \leqslant Z \leqslant n_{D}\right)$ grids and $N_{T}=\sum_{Z=1}^{n_{D}} n_{D, Z}$. The carbon dioxide emissions of each gird unit in the sub-region are $H_{z, i}\left(1 \leqslant Z \leqslant n_{D}, 1 \leqslant i \leqslant N_{d, z}\right)$.

Hence, the average carbon dioxide emissions of entire geographic space $\Omega$ are:

$$
H_{T}=\frac{1}{N_{T}} \sum_{i=1}^{N_{T}} H_{i}
$$

The sample variance of carbon dioxide emissions of entire geographic space $\Omega$ is:

$$
\sigma_{T}^{2}=\frac{1}{N_{T}} \sum_{i=1}^{N_{T}}\left(H_{i}-\bar{H}_{T}\right)^{2}
$$

The conceptual framework of the four geographical detectors (risk, factor, ecological and interaction) to be used in this paper is given in Table 1. Moreover, the detailed formula explanations are as follows.

Table 1. Conceptual framework of the Geographical detectors [21].

\begin{tabular}{cl}
\hline \multicolumn{1}{c}{ Detector } & \multicolumn{1}{c}{ Main Ideas } \\
\hline Risk detector & $\begin{array}{l}\text { Compares the differences in average carbon dioxide emissions rates between sub-regions } \\
\text { generated by a social economic factor. It uses t-tests to identify whether the average carbon } \\
\text { dioxide emissions rates among different sub-regions are significantly different. } \\
\text { Greater differences mean greater impact to carbon dioxide emissions within the sub-region. }\end{array}$ \\
\hline Factor detector & $\begin{array}{l}\text { Uses the } P D \text { to assess the impact of social economic factors on the spatial pattern of carbon } \\
\text { dioxide emissions. Higher PD means the social economic factor has a stronger contribution to } \\
\text { the occurrence of the carbon dioxide emissions. } \\
\text { It uses F-tests to compare whether the accumulated variance of each sub-region is significantly } \\
\text { different from the variance of the entire study region. }\end{array}$ \\
\hline Ecological detector & $\begin{array}{l}\text { Assesses whether the impacts of two social economic factors on the spatial distribution of } \\
\text { a carbon dioxide emissions are significantly different. } \\
\text { It also uses F-tests to compare the variance calculated in a sub-region attributed to one } \\
\text { influencing factor with the variance attributed to another influencing factor. }\end{array}$ \\
\hline $\begin{array}{l}\text { Consists of seven parts: Enhance, Enhance-bi, Enhancenonlinear, Weaken, Weaken-uni, } \\
\text { Weaken-nonlinear, and Independent. } \\
\text { It compares the combined contribution of two individual influencing factors to carbon dioxide } \\
\text { emissions, as well as their independent contributions. By doing so, it assesses whether the two } \\
\text { influencing factors weaken or enhance each another, or whether they independently influence } \\
\text { the development of the carbon dioxide emissions. }\end{array}$ \\
\hline
\end{tabular}


(1) Risk Detector

We assume that the influencing factor $\mathrm{D}$ divides geographic space into several sub-regions, among which two are denoted as $Z_{1}$ and $Z_{2}$, respectively. The average carbon dioxide emissions of these two sub-regions are:

$$
\begin{aligned}
& \overline{H_{z 1}}=\frac{1}{n_{D, z 1}} \sum_{i=1}^{n_{D, z 1}} H_{z 1, i} \\
& \overline{H_{z 2}}=\frac{1}{n_{D, z 2}} \sum_{i=1}^{n_{D, z 2}} H_{z 2, i}
\end{aligned}
$$

The sample variance of carbon dioxide emissions in these two sub-regions are:

$$
\begin{aligned}
& \sigma_{z 1}^{2}=\frac{1}{n_{D, z 1}} \sum_{i=1}^{n_{D, z 1}}\left(H_{z 1, i}-\overline{H_{z 1}}\right)^{2} \\
& \sigma_{z 2}^{2}=\frac{1}{n_{D, z 2}} \sum_{i=1}^{n_{D, z 2}}\left(H_{z 2, i}-{\overline{H_{z 2}}}^{2}\right.
\end{aligned}
$$

The average carbon dioxide emissions of each sub-region can be calculated by Formula (3). Similarly, we can also calculate the carbon dioxide emissions of each sub-region by $\overline{H_{Z 1}}$ and $\overline{H_{Z 2}}$. The carbon dioxide emissions of each sub-region may be different if differences existed between $\overline{H_{Z 1}}$ and $\overline{H_{Z 2}}$. Then, we will run some tests to find out whether they have significance. We will use $\mathrm{T}$ test to analyze their differences as follow [12]:

$$
t_{\overline{H_{z 1}}-\overline{H_{z 2}}}=\frac{\overline{H_{z 1}}-\overline{H_{z 2}}}{\left[\sigma_{z 1}^{2} / n_{D, z 1}+\sigma_{z 2}^{2} / n_{D, z 2}\right]^{1 / 2}}
$$

The degree of freedom is:

$$
d f=\frac{\sigma_{z 1}^{2} / n_{D, z 1}+\sigma_{z 2}^{2} / n_{D, z 2}}{\frac{1}{n_{D, z 1}-1}\left(\sigma_{z 1}^{2} / n_{D, z 1}\right)^{2}+\frac{1}{n_{D, z 2}-1}\left(\sigma_{z 2}^{2} / n_{D, z 2}\right)^{2}}
$$

We need to provide confidence level $\alpha$ (which is normally $5 \%$ ) to test null hypothesis $H_{0}: \overline{H_{z 1}}=\overline{H_{z 2}}$. If $\left|t_{\overline{H_{z 1}}}-\overline{H_{z 2}}\right|>t_{a / 2}$, we can refuse $\mathrm{H}_{0}$. It means that there are significant differences between these two sub-regions which are influence on carbon dioxide emissions. In contrast, the significant difference cannot be confirmed. Otherwise, the difference may be caused by system error.

(2) Factor detector

As influencing factor $D$ divides the entire geographic space into several sub-region, we can calculate layered total variance that caused by the division of influencing factor $D$.

$$
\sigma_{T D}^{2}=\frac{1}{N_{T, D}} \sum_{z=1}^{n_{D}} \sum_{i=1}^{n_{D, z}}\left(H_{z, i}-\overline{H_{z}}\right)^{2}
$$


where $N_{T, D}=\sum_{Z=1}^{n_{D}} n_{D, Z}$. If the influencing factor can completely affect carbon dioxide emissions, the sample variance of each sub-region is close to 0 [12], namely $\sigma_{T D}^{2}$ is close to 0 . Therefore, $P D$ value of factor $\mathrm{D}$ can be specifically expressed as follows:

$$
P D=1-\frac{\sigma_{T D}^{2}}{\sigma_{T}^{2}}
$$

We can tell from Formula (10) that $P D$ value is between 0 and 1 . When the $P D$ value equal to 1 , the value of $\sigma_{T D}^{2}$ is close to 0 , which means that this influencing factor has the same spatial distribution as the carbon dioxide emissions.

(3) Ecological detector

The ecological detector based on F-value test compares $D_{1}$ and $D_{2}$ and explores whether $D_{1}$ is more significant than $D_{2}$ in controlling the spatial pattern of the carbon dioxide emissions. If $D_{1}$ is more likely than $D_{2}$ to cause carbon dioxide emissions over space, we would expect the dispersion variance of $D_{1}\left(\sigma_{T D 1}^{2}\right)$ to be larger than that of $D_{2}\left(\sigma_{T D 2}^{2}\right)$. The test formula is:

$$
F=\frac{n_{T, D 1}\left(n_{T, D 1}-1\right) \sigma_{T D 1}^{2}}{n_{T, D 2}\left(n_{T, D 2}-1\right) \sigma_{T D 2}^{2}}
$$

This statistic is asymptotically distributed as $F\left(n_{T, D 1}-1, n_{T, D 2}-1\right)$ with $d f=\left(n_{T, D 1}, n_{T, D 2}\right)$. We need to provide confidence level $\alpha$ (which is normally $5 \%$ ) to test null hypothesis $H_{0}: \sigma_{T D 1}^{2}=\sigma_{T D 2}^{2}$.

If $H_{0}$ is rejected conditioned on a significant level $\alpha$ (usually $5 \%$ ) and, it means that there are significant differences between the two factors which have influence on carbon dioxide emissions.

(4) Interaction detector

We can apply interaction detector to analyze the effect of the interaction of two or more influencing factors on carbon dioxide emissions. The influence of two influencing factors $D_{1}$ and $D_{2}$ on carbon dioxide emissions may be independent or dependent. The influence on carbon dioxide emissions may be stronger or weaker after interaction. It compares the sum of the factors contribution of two individual attributes to the contribution of the two attributes when combined [12]:

Enhance: if $P D\left(D_{1} \cap D_{2}\right)>P D$ or $P D\left(D_{2}\right)$

Enhance, bivariate: if $P D\left(D_{1} \cap D_{2}\right)>P D$ and $P D\left(D_{2}\right)$

Enhance, nonlinear: if $\left.P D\left(D_{1} \cap D_{2}\right)\right\rangle P D\left(D_{1}\right)+P D\left(D_{2}\right)$

Weaken: if $P D\left(D_{1} \cap D_{2}\right)\left\langle P D\left(D_{1}\right)+P D\left(D_{2}\right)\right.$

Weaken, univariate: if $P D\left(D_{1} \cap D_{2}\right)\left\langle P D\left(D_{1}\right)\right.$ or $P D\left(D_{2}\right)$

Weaken, nonlinear: if $P D\left(D_{1} \cap D_{2}\right)\left\langle P D\right.$ and $P D\left(D_{2}\right)$

Independent: if $P D\left(D_{1} \cap D_{2}\right)=P D\left(D_{1}\right)+P D\left(D_{2}\right)$

where the symbol " $\cap$ " denotes the intersection between $D_{1}$ and $D_{2}$. "PD $\left.\left(D_{1} \cap D_{2}\right)\right\rangle P D$ or $P D\left(D_{2}\right)$ " is not equivalent to " $\left.P D\left(D_{1} \cap D_{2}\right)\right\rangle P D$ and $P D\left(D_{2}\right)$ " e.g., assume that $P D\left(D_{1}\right)=0.2, P D\left(D_{2}\right)=0.5$ and $P D\left(D_{1} \cap D_{2}\right)=0.3$; then " $\left.0.3\left(D_{1} \cap D_{2}\right) 0.2\right\rangle\left(D_{1}\right)$ or $0.5\left(D_{2}\right)$ " is true, but the " $\left.0.3\left(D_{1} \cap D_{2}\right)\right\rangle 0.2\left(D_{1}\right)$ and $0.5\left(D_{2}\right)$ " is not valid. It could be "0.3( $\left.D_{1} \cap D_{2}\right)\left\langle 0.2\left(D_{1}\right)+0.5\left(D_{2}\right)\right.$ (Weaken)" and also "0.3 $\left(D_{1} \cap D_{2}\right)>0.2\left(D_{1}\right)$ (Enhance)", in which case the conclusion is that the $D_{1}$ and $D_{2}$ joint risk (0.3) enhances the $D_{1}$ single risk (0.2) but is smaller than the two individual risks added together $(0.2+0.5)$.

\section{Results}

\subsection{Spatial Distribution of Carbon Dioxide Emissions and Influencing Factors}

There is a significant difference between the spatial pattern of carbon dioxide emissions and the social economic factors of 101 counties in the Inner Mongolia, China. Table 2, Figures 1 and 2 
present the quantitative statistics, spatial pattern of carbon dioxide emissions and six social economic factors, respectively. The distribution of carbon dioxide emissions and influencing factors significantly varied across Inner Mongolia (Figures 1 and 2). The maximum and minimum values of carbon dioxide emissions were greatly different. In some counties, the carbon dioxide emissions were less than 0.02 million tons, while in other counties, it reached 6999.58 million tons. The average carbon dioxide emissions are 505.43 million tons. The carbon dioxide emissions of the southwestern of Inner Mongolia, where are the traditional heavy industry concentrated cities such as Huhhot and Baoto, are higher than other regions. In particular, the carbon dioxide emissions of the east and north regions are lower; this is consistent with the location of prairies and forests (Figure 1).

Table 2. The distribution of carbon dioxide emissions and influencing factors.

\begin{tabular}{lccccccc}
\hline \multicolumn{1}{c}{ Variables } & Mean & STD & Min & $\mathbf{2 5 \%}$ & $\mathbf{5 0 \%}$ & $\mathbf{7 5 \%}$ & Max \\
\hline Carbon dioxide emissions (million $\mathrm{t})$ & 505.43 & 971.84 & 0.02 & 25.95 & 80.71 & 608.75 & 6999.58 \\
GDP $\left(10^{8} \mathrm{CNY}\right)$ & 175.15 & 193.62 & 12.73 & 58.17 & 103.59 & 212.47 & 1000.4 \\
Economic growth rate (\%) & 13 & 3.44 & 4.2 & 11.1 & 13.3 & 15.1 & 24.9 \\
Industrial structure (\%) & 2.42 & 1.77 & 0.2 & 1.3 & 1.9 & 3.1 & 9.4 \\
Population (million people) & 24.86 & 16.74 & 1.79 & 10.9 & 23.26 & 33.95 & 88.96 \\
Urbanization rate (\%) & 49.7 & 28.52 & 8.34 & 22.27 & 49.97 & 74.89 & 100 \\
Road density $\left(\mathrm{km} / \mathrm{km}^{2}\right)$ & 0.03 & 0.08 & 0 & 0 & 0.01 & 0.01 & 0.64 \\
\hline
\end{tabular}

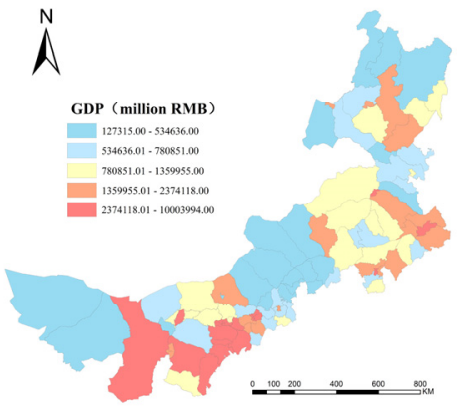

(a) GDP

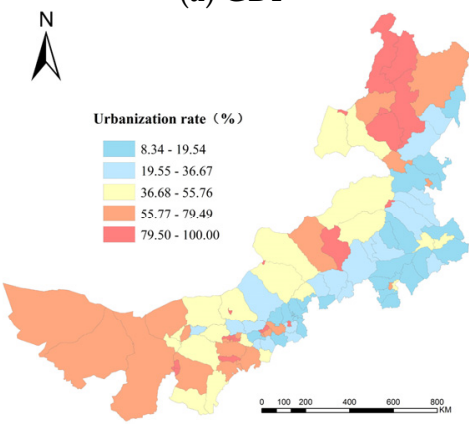

(d) Urbanization

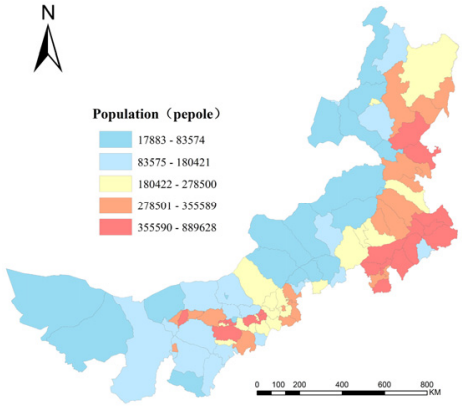

(b) Population

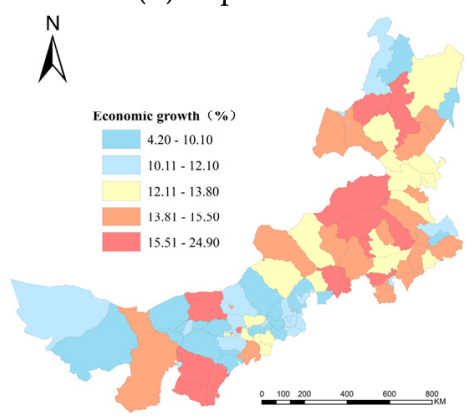

(e) Economic growth

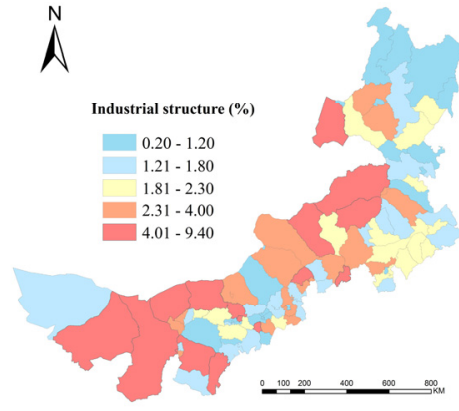

(c) Industrial Structure

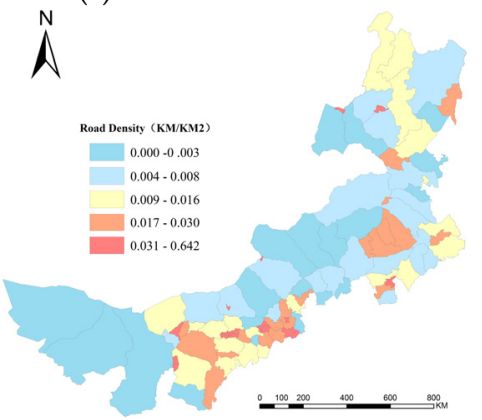

(f) Road density

Figure 2. The spatial distribution of influencing factors of carbon dioxide emissions at the county level in Inner Mongolia, China.

The average GDP of each county in Inner Mongolia is 175.15 billion yuan. The wealth gap in Inner Mongolia is significant as the highest GDP is 1000.4 billion yuan and lowest is 12.73 billion yuan. We can find that high GDP areas are mostly distributed at Huhhot and Baotou, where the main developed cities in Inner Mongolia are (Figure 2A). As to population distribution, it gradually decreases from northeast to southwest (Figure 2B). The industrial structure is higher in the middle and lower at two poles (Figure 2C). Urbanization rate and economic growth rate have the same spatial distribution tendency, namely in the northeast it is relatively high and in the southeast it is extremely low (Figure 2D,E). 
The spatial pattern of road density is similar to that of GDP. This means that the road density in Baotou and Huhhot is more concentrated than in other areas (Figure 2F). The reason is that Baotou and Huhhot is the key economic bond of Inner Mongolia, China. The areas with higher GDP have economically developed and more agglomerated traffic.

\subsection{Spatial Correlation Analysis of Carbon Dioxide Emissions and Influencing Factors}

The spatial autocorrelation pattern of carbon dioxide emissions and social economic factors in Inner Mongolia, China is significantly different. The global Morans'I indicators of social economic factors are: GDP $(0.42)>$ population $(0.42)>$ urbanization rate $(0.41)>$ economic growth rate $(0.29)>$ industrial structure $(0.22)>$ road density $(0.27)>$ carbon dioxide emissions $(0.07)>(p \leqslant 0.05)$. GDP has extremely high positive spatial autocorrelation. The positive spatial autocorrelation of population is also extremely high. The positive spatial autocorrelation of other factors is not distinct, which means they have higher randomness in terms of spatial distribution.

In this study, we use the Pearson correlation index to examine the correlation of social economic factors in Inner Mongolia, China. As a result of the correlation test between the independent variables (Table 3) we found that the correlation index of GDP and carbon dioxide emissions is 0.52 and the correlation index of GDP and population is 0.44 . The correlation index among other variables is not very high. Most of the social economic factors are positive correlated, but GDP, industrial structure and population industrial structure, economic growth rate and urbanization rate and industrial structure and urbanization rate are negatively correlated. Generally, these six factors have low correlation. Thus, they can be incorporated into the multi-variant geographical detector model.

Table 3. The result of the correlation test between the independent variables.

\begin{tabular}{cccccccc}
\hline & $\begin{array}{c}\text { Carbon } \\
\text { Dioxide } \\
\text { Emissions }\end{array}$ & GDP & Population & $\begin{array}{c}\text { Economic } \\
\text { Growth } \\
\text { Rate }\end{array}$ & $\begin{array}{c}\text { Industrial } \\
\text { Structure }\end{array}$ & $\begin{array}{c}\text { Urbanization } \\
\text { Rate }\end{array}$ & $\begin{array}{c}\text { Road } \\
\text { Density }\end{array}$ \\
\hline Carbon dioxide emissions & 1 & & & & & & \\
GDP & 0.52 & 1 & & & & & \\
Population & 0.13 & 0.44 & 1 & & & & \\
Economic growth rate & 0.02 & 0 & -0.06 & 1 & & & 1 \\
Industrial Structure & 0.07 & -0.17 & -0.42 & 0.18 & 1 & & \\
Urbanization rate & 0.2 & 0.36 & -0.23 & 0.06 & -0.04 & 1 \\
Road Density & 0.16 & 0.40 & 0.12 & 0.12 & -0.08 & 0.26 & 1 \\
\hline
\end{tabular}

\subsection{Analysis of Influencing Factors of Carbon Dioxide Emissions Based on Geographical Detector Model}

\subsubsection{Risk Detector}

In order to analyze the influence of social economic factors on carbon dioxide emissions with risk detector, we need to discrete these factors, and then turn original continuous data into layered [17]. In this study, we have applied multiple sorting techniques, such as natural breakpoint classification, evenly spaced classification, evenly divided classification, and natural breakpoint classification. Finally, natural breakpoint classification is selected for a better result.

Table 4 shows the effect of GDP on the increase of carbon dioxide emissions. What we can know from Table 4 is that when GDP $<53$ billion yuan, carbon dioxide emissions is 86.06 million tons. With the increase of GDP, carbon dioxide emissions are also increasing gradually. When GDP > 237 billion yuan, carbon dioxide emissions are 2006.99 million tons. It indicates that counties with higher GDP have higher risk of carbon dioxide emissions. This suggests that there is strong correlation between the increase of the carbon dioxide emissions and GDP. Table 5 shows the influence of industrial structure on carbon dioxide emissions. When the industrial structure is high, the carbon dioxide emission is also high. When the industrial structure is higher than $4.0 \%$, the carbon dioxide emissions are 669.93 million tons. This finding indicates that there is a strong correlation between industrial structure and the carbon 
dioxide emissions. We undertake the risk detector to analyze the correlation between other influencing factors and the carbon dioxide emissions with similar analysis.

Table 4. Average carbon dioxide emissions according to the GDP.

\begin{tabular}{cccccc}
\hline GDP (Million Yuan) & $<\mathbf{5 3}$ & $\mathbf{5 3 - 7 8}$ & $\mathbf{7 8 - 1 3 6}$ & $\mathbf{1 3 6 - 2 3 7}$ & $>\mathbf{2 3 7}$ \\
\hline Carbon dioxide emissions (million $\mathrm{t})$ & 86.06 & 77.96 & 178.67 & 528.37 & 2006.99 \\
\hline
\end{tabular}

Table 5. Average carbon dioxide emissions according to the industrial structure.

\begin{tabular}{cccccc}
\hline Industrial Structure (\%) & $<\mathbf{1 . 2}$ & $\mathbf{1 . 2 - 1 . 8}$ & $\mathbf{1 . 8 - 2 . 3}$ & $\mathbf{2 . 3 - 4 . 0}$ & $>\mathbf{4 . 0}$ \\
\hline Carbon dioxide emissions (million t) & 111.20 & 113.32 & 336.27 & 501.67 & 669.93 \\
\hline
\end{tabular}

\subsubsection{Factor Detector}

We applied factor detector to determine the influence of six factors on carbon dioxide emissions. The $P D$ values are ranked as follows: GDP $(0.37)>$ population $(0.20)>$ economic growth rate $(0.09)>$ road density $(0.07)>$ industrial structure $(0.05)>$ urbanization rate $(0.05)$. It indicates that GDP has the highest influence on carbon dioxide emissions, which is consistent with the result of risk detector. The population is the second, which means population contributes to the increase of carbon dioxide emissions. Economic growth rate also has a great influence on carbon dioxide emissions. The influence of economic growth rate on carbon dioxide emissions shows that industrial production is the main reason for causing amount of carbon dioxide emissions in Inner Mongolia, China at the current stage.

\subsubsection{Ecological Detector}

In this study, an ecological detector is used to find out that the significant difference of the influence of six social economic factors on carbon dioxide emissions (Table 6). The result shows that the differences in $P D$ values between each two of the population and economic growth rate, population and road density rate does not have significant difference on carbon dioxide emissions. However, the influence between variables in the first group and the variables in the second group has significant difference on carbon dioxide emission. Thus, combining with the result of factor detector and ecological detector, we find out that GDP and population have a significant effect on carbon dioxide emissions.

Table 6. Statistical significance of all variables using the ecological detector.

\begin{tabular}{cccccc}
\hline & GDP & Population & $\begin{array}{c}\text { Economic } \\
\text { Growth Rate }\end{array}$ & $\begin{array}{c}\text { Industrial } \\
\text { Structure }\end{array}$ & $\begin{array}{c}\text { Urbanization } \\
\text { Rate }\end{array}$ \\
\hline GDP & Y & & & & \\
Population & $\mathrm{Y}$ & $\mathrm{N}$ & & & \\
Economic growth rate & $\mathrm{Y}$ & $\mathrm{Y}$ & $\mathrm{N}$ & & \\
Industrial structure & $\mathrm{Y}$ & $\mathrm{Y}$ & $\mathrm{N}$ & $\mathrm{N}$ & $\mathrm{N}$ \\
Urbanization rate & $\mathrm{Y}$ & $\mathrm{N}$ & $\mathrm{N}$ & $\mathrm{N}$ & $\mathrm{N}$ \\
Road density & $\mathrm{Y}$ & & \\
\hline
\end{tabular}

\subsubsection{Interaction Detector}

At last, interaction detector is used to detect the influence of interaction of each two social economic factors on carbon dioxide emissions. We can find from Table 7 that the effects of influence of interaction of GDP and population, GDP and industrial structure on carbon dioxide emission are independent. The effects of other interactive factors on carbon dioxide emissions are combined, which means the effect of these factors on carbon dioxide emissions will be greater after interaction. For instance, the $P D$ value of GDP is 0.37 , and the $P D$ value of economic growth rate is 0.09 . After their 
interaction, the $P D$ value reached 0.51 . It shows that the interaction among these two factors has great intensity. Although the $P D$ value (0.05) of industrial structure is higher than road density $(0.07)$ and the $P D$ value of the interaction of industrial structure and urbanization rate is only 0.13 , which is far less than the $P D$ value (0.44) of interaction of road density and urbanization rate. The $P D$ value reaches 0.71 after interaction of GDP and road density, which is far higher than their separate influence on carbon dioxide emissions. This indicates that the economic growth in Inner Mongolia is mainly driven by industrial production, which is an extensive growth pattern.

Table 7. Power of Determinant $(P D)$ values for interactions between pairs of factors on the carbon dioxide emissions.

\begin{tabular}{ccccccc}
\hline & GDP & Population & $\begin{array}{c}\text { Economic } \\
\text { Growth Rate }\end{array}$ & $\begin{array}{c}\text { Industrial } \\
\text { Structure }\end{array}$ & $\begin{array}{c}\text { Urbanization } \\
\text { Rate }\end{array}$ & $\begin{array}{c}\text { Road } \\
\text { Density }\end{array}$ \\
\hline GDP Population & $0.43-$ & & & & \\
Economic growth rate & $0.51 \uparrow$ & $0.37 \uparrow$ & & & \\
Industrial structure & $0.40-$ & $0.34 \uparrow$ & $0.37 \uparrow$ & & \\
Urbanization rate & $0.48 \uparrow$ & $0.44 \uparrow$ & $0.44 \uparrow$ & $0.13 \uparrow$ & \\
Road density & $0.71 \uparrow$ & $0.30 \uparrow$ & $0.29 \uparrow$ & $0.32 \uparrow$ & $0.38 \uparrow$ & \\
\hline
\end{tabular}

$\uparrow$ : After interaction of two factors, the interaction effects on carbon dioxide emissions is more than their individual effect, namely combined; -: After interaction, the effect on carbon dioxide emissions is greater than the effect of individual effect. However, it is less than the sum of their effect on carbon dioxide emissions, which is independent.

\section{Conclusions and Discussion}

In this study, we used four geographical detectors to assess effects of influencing factors on the carbon dioxide emissions. We believe this method to be novel in that it extracts the interrelationships between environmental problem and influencing factors by the correspondence of their spatial distribution. Moreover, it is easy to implement. To our knowledge, this is the first study on the effect of different industries and different counties on the carbon dioxide emissions in Inner Mongolia, China.

We found that (1) Inner Mongolia is suffering from a great gap between the rich and the poor, carbon dioxide emission is very uneven and regional difference is highly significant. With the development of GDP and industrial structure, carbon dioxide emissions are gradually increasing, but there is no significant difference in carbon dioxide emissions when population, economic growth rate and urbanization rate reach a certain number or a certain level. Road density has no distinct influence on carbon dioxide emission; (2) The influence of social economic factors on carbon dioxide emissions is as follows: GDP $(0.37)>$ population $(0.20)>$ economic growth rate $(0.09)>$ road density $(0.07)>$ industrial structure $(0.05)>$ urbanization rate (0.05). Therefore, we know that GDP and population have played an important role in the emissions of carbon dioxide in Inner Mongolia, China. In spite of the strong positive autocorrelation of GDP and carbon dioxide emissions, GDP and population, other factors are relatively randomly distributed in space; (3) In addition, the combination of two environmental factors strengthened the emissions of carbon dioxide. Most previous studies simultaneously considered the influence of a single social economic factor on carbon dioxide emissions. However, the emissions of carbon dioxide are complex. Our study showed that the interactive detector could simultaneously estimate the effect of two or even more factors on the carbon dioxide emissions. Finally, to our best knowledge, this is the first study that applies the geographical detector model to analyze the influence of the social economic factors on carbon dioxide emissions in the Inner Mongolia, China quantitatively.

In this paper, we discuss short, medium and long term goals for low carbon development in China in the introduction sector. It is vital for Inner Mongolia not only ensure economic growth, but also to reduce carbon emissions. According to the obtained above results, we propose carbon emission reduction strategies as follows: we should break away from the traditional mode of economic growth such as "high input, high consumption", strengthen industry structure gradual by adjusting 
industry structure from "two, three or one" to "three, two or one" and appropriate together with controlling energy resources development, increase the technology content from a resource-intensive to technology-intensive industries; and encourage the introduction of low-carbon technologies, especially for high energy-consuming industries, which not only achieves technical and economic feasibility, but also achieves economic and environmental sustainability in Inner Mongolia.

One limitation of this research is the discretization of quantitative data. The geographical detector model is very effective for the analysis of qualitative data, but ineffective for the quantitative data. The quantitative data needs to be discredited at first. Then it should be classified into different grades [21]. After this, a geographical detector can be used for the final analysis. In this study, the geographical detector model chooses the natural breakpoint classification through comparing the natural breakpoint classification (natural break), spaced classification (quantize) and divided classification (equal interval). How to effectively discredit quantitative data is the problem that needs to be solved in future research [12,22]. The other limitation of this study is that it only estimated energy consumption of the industrial sector, therefore future research should consider other sectors connected to carbon dioxide emissions. Additionally, future studies should divide the fossil fuels into different types of fuel such as washed coal i.e., in order to study the impact of different types of energy on carbon dioxide emissions. Finally, future studies could consider various factors such as carbon dioxide emissions intensity, energy consumption intensity impact on carbon dioxide emissions. We believe that this issue will deserve further attention in future study.

Acknowledgments: This study is supported by the National Key Technology R\&D Program of China under Grant Nos.2013BAK05B01 and 2013BAK05B02 and National Natural Science Fund of China under Grant No.41161060. We wish to thank Jixia Huangfor his analyzing software and fruitful discussions, Mingxiang Huang for his kind hospitality and for sharing his knowledge about carbon dioxide emissions with us. The authors are also grateful to the anonymous reviewers for their insightful and helpful comments to improve the manuscript.

Author Contributions: All authors contributed to the data extraction. Rina Wu designed the methods, and Rina $\mathrm{Wu}$ and Jiquan Zhang undertook the data analysis. All authors contributed to the drafting of the article and approved the final manuscript.

Conflicts of Interest: The authors declare no conflict of interest.

\section{References}

1. Wang, L.M.; He, K.L. Analysis of spatial variations in environmental impact based on the STIRPAT model-A case study of energy consumption. Acta Sci. Circumst. 2008, 28, 1032-1037.

2. Philip, K.A.; William, B.; Franklin, A.M.; Justice, T.M.; Ebo, B. Carbon dioxide emissions, economic growth, industrial structure, and technical efficiency: Empirical evidence from Ghana, Senegal, and Morocco on the causal dynamics. Energy 2012, 47, 314-325.

3. Wang, W.W.; Zhang, M.; Zhou, M. Using LMDI method to analyze transport sector $\mathrm{CO}_{2}$ emissions in China. Energy 2011, 36, 5909-5915. [CrossRef]

4. Lee, C.C.; Chang, C.P. Energy consumption and economic growth in Asian economies: A more comprehensive analysis using panel data. Resour. Energy Econ. 2008, 30, 50-65. [CrossRef]

5. Ehrlich, P.R.; Holden, J.P. Impact of population growth. Science 1971, 171, 1212-1217. [CrossRef] [PubMed]

6. York, R.; Rosa, E.; Dietz, T. STIRPAT, IPAT and Impact: Analytic tools for unpacking the influencing forces of environmental impacts. Ecol. Econ. 2003, 46, 351-365. [CrossRef]

7. Lin, S.F.; Zhao, D.T.; Dora, M. Analysis of the environmental impact of China based on STIRPAT model. Environ. Impact Assess. Rev. 2009, 29, 341-347. [CrossRef]

8. Kaika, D.; Zervas, E. The Environmental Kuznets Curve (EKC) theory-Part A: Concept, causes and the $\mathrm{CO}_{2}$ emissions case. Energy Policy 2013, 62, 1392-1402. [CrossRef]

9. Xu, X.Y.; Ang, B.W. Index decomposition analysis applied to $\mathrm{CO}_{2}$ emission studies. Ecol. Econ. 2013, 93, 313-329. [CrossRef]

10. Su, B.; Ang, B.W. Structural decomposition analysis applied to energy and emissions: Some methodological developments. Energy Econ. 2012, 34, 177-188. [CrossRef] 
11. Ang, B.W. LMDI decomposition approach: A guide for implementation. Energy Policy 2015, 86, 33-238. [CrossRef]

12. Wang, J.F.; Li, X.H.; Christakos, G.; Liao, Y.L.; Zhang, T.; Gu, X. Geographical detectors-based health risk assessment and its application in the neural tube defects study of the Heshun Region, China. Int. J. Geogr. Inf. Sci. 2010, 24, 107-127. [CrossRef]

13. Hu, Y.; Wang, J.F.; Li, X.H.; Ren, D.; Zhu, J. Geographical Detector-Based Risk Assessment of the Under-Five Mortality in the 2008 Wenchuan Earthquake, China. PLoS ONE 2011, 6, e21427. [CrossRef] [PubMed]

14. Allen, M.P. Regression Analysis with Dummy Variables. Understanding Regression Analysis; Plenum Press: New York, NY, USA, 1997; pp. 128-132.

15. Huang, J.X.; Wang, J.F.; Bo, Y.C.; Xu, C.D.; Hu, M.G.; Huang, D.C. Identification of Health Risks of Hand, Foot and Mouth Disease in China Using the Geographical Detector Technique. Int. J. Environ. Res. Public Health 2014, 11, 3407-3423. [CrossRef] [PubMed]

16. Inner Mongolia Statistical Yearbook. 2012. Available online: http://nianjian.xiaze.com/info/nmgtjnj.html (accessed on 15 November 2012).

17. Intergovernmental Panel on Climate Change. IPCC Guidelines for National Greenhouse Gas Inventories; Intergovernmental Panel on Climate Change: Geneva, Switzerland, 2007.

18. Eldridge, H.T. Population growth and economic development. Land Econ. 1952, 28, 1-9. [CrossRef]

19. Wu, J.R.; Yang, Z.P.; Adayi, S. Impact factors and temporal variation of environmental pressure of Xinjiang based on ATIRPAT model. Arid Land Geogr. 2011, 34, 187-192.

20. Maslow, A.H. A theory of human motivation. Psychol. Rev. 1943, 50, 370-396. [CrossRef]

21. Cao, F.; Ge, Y.; Wang, J.F. Optimal discretization for geographical detectors-based risk assessment. GIS Sci. Remote Sens. 2013, 50, 78-92.

22. Wang, J.F.; Hu, Y. Environmental health risk detection with GeogDetector. Environ. Model. Softw. 2012, 33, 114-115. [CrossRef]

(C) 2016 by the authors; licensee MDPI, Basel, Switzerland. This article is an open access article distributed under the terms and conditions of the Creative Commons by Attribution (CC-BY) license (http:/ / creativecommons.org/licenses/by/4.0/). 